\title{
Silagens de capim-elefante (Pennisetum purpureum Schum.) aditivadas com resíduo de açaí (Euterpe oleracea)
}

\author{
Elephant grass silages (Pennisetum purpureum Schum.) with acai residue (Euterpe oleracea) \\ Ensilajes de pasto elefante (Pennisetum purpureum Schum.) con residuo de açaí (Euterpe oleracea)
}

\section{Resumo}

Durante a estiagem, o déficit hídrico faz com que as gramíneas apresentem baixa qualidade, além de causar redução na oferta desse volumoso, assim, a ensilagem é uma alternativa, pois preserva forragens, para alimentar os animais nesse período. Objetivou-se avaliar silagens de capim-elefante aditivadas com resíduo de açaí sobre as características sensoriais, o padrão fermentativo, estabilidade aeróbia e composição químico-bromatológica. Os tratamentos consistiram na silagem de capim elefante com inclusão de 0 e $15 \%$ de resíduo na matéria natural, com 5 repetições. $\mathrm{O}$ capim foi oriundo da Fazenda Experimental da Ufopa. O resíduo do açaí foi coletado em 4 pontos de vendas distintos (Natureza, Tapajós, Nativo e Alemão). O valor médio de $\mathrm{pH}$ das silagens foi de 3,86. A média de temperatura dos tratamentos foi de $24,35^{\circ} \mathrm{C}$. A silagem sem adição de açaí apresentou menor teor de matéria seca $(247,82 \mathrm{~g} / \mathrm{kg})$. A silagem sem resíduo de açaí apresentou menor teor de FDN $(631,24 \mathrm{~g} / \mathrm{kg})$. O tratamento com adição de resíduo do açaí Nativo apresentou maior teor de PB $(70,42 \mathrm{~g} / \mathrm{kg})$ em relação à silagem Natureza $(58,62)$. Quanto ao nitrogênio amoniacal, o tratamento Tapajós obteve o maior teor (3,6\%). As silagens sem adição de açaí e Alemão mantiveram-se estáveis durante o período de exposição ao ar. Conclui-se que a adição de $15 \%$ de resíduo de açaí ao capim-elefante para ensilagem mantém as características sensoriais de silagens de boa qualidade nutritiva, aumenta os teores de MS e de FDN e reduz a MM. As silagens de capim-elefante e Alemão apresentaram melhor estabilidade aeróbia.

Palavras-chave: Aditivo; Estabilidade aeróbia; Fermentação anaeróbia.

\begin{abstract}
During the dry season, the water deficit makes the grasses have low quality, in addition to reducing the supply of this forage, thus, silage is an alternative, as it preserves forage, to feed the animals during this period. The aim of this study was to evaluate elephant grass silages with acai residue on sensory characteristics, fermentation pattern, aerobic stability and chemical-bromatological composition. The treatments consisted of elephant grass silage with inclusion of 0 and $15 \%$ of residue in the natural matter, with 5 repetitions. The grass came from UFOPA's Experimental Farm. The açaí residue was collected at 4 different points of sale (Natureza, Tapajós, Nativo and Alemão). The mean pH value of
\end{abstract}


the silages was 3.86 . The average temperature of the treatments was $24.35^{\circ} \mathrm{C}$. Silage without the addition of açaí had lower dry matter content $(247.82 \mathrm{~g} / \mathrm{kg})$. Silage without açaí residue had lower NDF content $(631.24 \mathrm{~g} / \mathrm{kg})$. The treatment with addition of residue from Açaí Nativo showed higher CP content $(70.42 \mathrm{~g} / \mathrm{kg})$ compared to Nature silage (58.62). As for ammonia nitrogen, the Tapajós treatment had the highest content (3.6\%). Silages without the addition of açaí and Alemão remained stable during the period of exposure to air. It is concluded that the addition of $15 \%$ of açaí residue to elephant grass for ensiling maintains the sensory characteristics of silages of good nutritional quality, increases the DM and NDF contents and reduces the MM. Elephant grass and Alemão silage showed better aerobic stability.

Keywords: Additive; Aerobic stability; Anaerobic fermentation.

\section{Resumen}

Durante la época seca, el déficit hídrico hace que las gramíneas tengan baja calidad, además de reducir el aporte de este forraje, por lo que el ensilado es una alternativa, ya que conserva el forraje, para alimentar a los animales durante este período. El objetivo de este estudio fue evaluar ensilajes de pasto elefante con residuo de açaí en características sensoriales, patrón de fermentación, estabilidad aeróbica y composición químico-bromatológica. Los tratamientos consistieron en ensilaje de pasto elefante con inclusión de 0 y $15 \%$ de residuo en la materia natural, con 5 repeticiones. La hierba vino de la Granja Experimental de la UFOPA. El residuo de açaí se recogió en 4 puntos de venta diferentes (Natureza, Tapajós, Nativo y Alemão). El valor medio del pH de los ensilajes fue de 3,86. La temperatura promedio de los tratamientos fue de $24,35^{\circ} \mathrm{C}$. El ensilado sin adición de açaí tuvo menor contenido de materia seca $(247,82 \mathrm{~g} / \mathrm{kg})$. El ensilado sin residuo de açaí tuvo menor contenido de FDN (631,24 g/kg). El tratamiento con adición de residuo de Nativo açaí tuvo un mayor contenido de PB $(70,42 \mathrm{~g} / \mathrm{kg})$ en relación al ensilado Nature $(58,62)$. En cuanto al nitrógeno amoniacal, el tratamiento Tapajós presentó el mayor contenido $(3,6 \%)$. Los ensilajes sin la adición de açaí y Alemão se mantuvieron estables durante el período de exposición al aire. Se concluye que la adición de $15 \%$ de residuo de açaí al pasto elefante para ensilado mantiene las características sensoriales de ensilados de buena calidad nutricional, aumenta los contenidos de MS y FDN y reduce la MM. El ensilado de pasto elefante y alemão mostró una mejor estabilidad aeróbica.

Palabras clave: Aditivo; Estabilidad aeróbica; Fermentación anaeróbica.

\section{Introdução}

Caracterizado por forte sazonalidade climática, o Brasil apresenta basicamente dois períodos distintos, um de estiagem e outro de alta precipitação pluviométrica. No período chuvoso, a oferta de alimento para os rebanhos é bastante favorecida, enquanto que no período de seca as gramíneas tropicais, utilizadas em pastagens brasileiras, apresentam redução na qualidade e na produção, havendo, portanto, a necessidade de adoção de práticas de manejo visando manter a alimentação do rebanho no período de escassez de alimentos e, consequentemente, minimizar os efeitos negativos na produção animal durante esse período.

Fazendo parte das diversas tecnologias que contribuem incrementando os índices de produtividade dos empreendimentos rurais, principalmente aqueles onde a área é limitada, está a conservação do excedente da forragem produzida em épocas chuvosas com intuito de uso durante a seca, sendo esta técnica umas das mais flexíveis e viáveis a serem adotadas (Cândido \& Furtado, 2020).

O açaizeiro (Euterpe oleracea Mart.) é nativo da Amazônia brasileira e a dispersão natural dessa palmácea tem como principal centro o Estado do Pará.

Em 2018, o Estado do Pará apresentou um volume anual de produção de açaí de 1.439.249 toneladas de frutos. Sendo comercializados pelo estado, mais de 788,4 milhões de reais em produtos obtidos pelo beneficiamento do açaí, destinados aos mercados nacional e internacional, que adquiriram 182.943 toneladas de polpa, mixes, açaí liofilizado e in natura, proporcionando um acréscimo de 12,97\% no volume em relação ao ano de 2017 (Tavares, Homma, Menezes \& Palheta, 2020).

São crescentes as pesquisas com inclusão de aditivos ricos em matéria seca com poder de absorver a umidade e também proporcionar incremento no valor nutritivo da silagem (Borges et al., 2018). Desta forma, em regiões com potencial produtivo de alimentos, através de conservação de forragens, os subprodutos têm potencial para uso na alimentação animal.

Nogueira (2015) em sua avaliação de silagem de palma forrageira aditivada com farelo de trigo e ureia constatou a ocorrência de um gel emulsificante que retia os fluidos celulares após o rompimento das células da planta, resultando em 
baixas perdas por efluentes (cerca de 22 e $25 \mathrm{~kg} / \mathrm{t}$ de matéria natural).

Araújo (2016), avaliando diferentes níveis de inclusão de açaí na silagem de capim-canarana, verificou que a inclusão de até $15 \%$ de caroço triturado de açaí na silagem não afeta as perdas de matéria seca e qualidade fermentativa, contribuindo com os aspectos nutricionais da silagem; além disso, apresentou baixa estabilidade aeróbia e que a inclusão de até $15 \%$ de caroço de açaí ajuda a aumentar a estabilidade.

Desta forma, a utilização do subproduto agroindustrial do açaí surge como uma alternativa de alimentação para o rebanho em período seco, podendo prolongar o armazenamento e o aproveitamento na forma de silagem (Amaral et al., 2021); além de minimizar a dispersão desses resíduos no meio, provendo sustentabilidade ambiental.

Objetivou-se com o presente trabalho avaliar a silagem de capim-elefante (Pennisetum purpureum Schum.) com inclusão de $15 \%$ de resíduo de açaí (Euterpe oleracea) oriundos de diferentes pontos de coletas, verificando se as diferentes origens deste aditivo causam diferentes efeitos quanto às características sensoriais e nutricionais, o padrão fermentativo, a composição químico-bromatológica e a estabilidade aeróbia.

\section{Metodologia}

O presente trabalho trata-se de uma pesquisa experimental, com dados quantitativos (Pereira et al., 2018). O experimento foi realizado no Laboratório de Bromatologia da Universidade Federal do Oeste do Pará - UFOPA, localizado no município de Santarém-Pará.

O capim-elefante foi oriundo da Fazenda Experimental da Ufopa, coletado de forma manual a $10 \mathrm{~cm}$ do solo. Os resíduos do açaí foram coletados em 4 pontos distintos de vendas (batedores): Natureza, Tapajós, Nativo e Alemão, no município de Santarém-PA.

Os tratamentos consistiram na silagem de capim-elefante com 15\% de inclusão do resíduo de açaí na matéria natural, em que: CAPIM-ELEFANTE: 0\% de resíduo de açaí; NATUREZA: 15\% de resíduo de açaí do batedor Natureza; TAPAJÓS: 15\% de resíduo de açaí do batedor Tapajós; NATIVO: 15\% de resíduo de açaí do batedor Nativo; ALEMÃO: 15\% de resíduo de açaí do batedor Alemão, com cinco repetições cada.

O fruto açaí é coletado pelos produtores nas áreas rurais próximas à cidade, transportado até os batedores onde passa por processos estabelecidos pelo decreto $\mathrm{n}^{\circ} 326$, de 20 de janeiro de 2012, que dispões das regras para cadastramento dos batedores artesanais de açaí e bacaba; condições higiênico-sanitárias, máquinas e equipamentos, padrões para instalações, materiais; e boas práticas de processamento, e atividades de inspeção e fiscalização.

Os materiais foram picados com o auxílio de uma picadeira estacionária. Após, foi realizado o pré-emurchecimento ao sol por 2 horas, para retirada de parte da umidade, e misturados manualmente com o nível de $15 \%$ de resíduo de açaí.

Do material antes de ensilar, para a determinação da composição químico-bromatológica in natura, foram retiradas de cada repetição $300 \mathrm{~g}$, acondicionadas em marmitas de alumínio e levadas à estufa com ventilação forçada de ar a $55^{\circ} \mathrm{C}$ durante 72 horas. Posteriormente.

Para a produção da silagem, os materiais foram compactados manualmente em silos experimentais, devidamente identificados, confeccionados em material de PVC, com $35 \mathrm{~cm}$ de altura por $10 \mathrm{~cm}$ de diâmetro, de modo a atingirem densidade de $600 \mathrm{~kg} / \mathrm{m}^{3}$ (1,650 kg de silagem em cada silo), fechados com tampas equipadas com válvulas de Bunsen, para escape dos gases oriundos da fermentação, vedados e armazenados por 30 dias.

Os silos experimentais foram pesados no início e no final do período experimental, para a determinação das perdas por gases durante o processo de fermentação da silagem.

Logo após a abertura, os primeiros $5 \mathrm{~cm}$ de silagem foram descartados, e em seguida foram realizadas mensurações da temperatura no interior dos silos, inserindo um termômetro digital no centro de cada um, em profundidade de $10 \mathrm{~cm}$, 
posteriormente, todo o material foi retirado colocado em bandeja plástica, homogeneizado e realizada a análise sensorial, de acordo com Meyer et al. (1989), quanto aos aspectos relacionados ao valor nutritivo e conservação das silagens.

Após a análise sensorial, foram retiradas amostras para a determinação dos valores de $\mathrm{pH}$ das silagens, conforme metodologia descrita por Silva e Queiroz (2002).

Para as análises da composição bromatológica foram retirados $300 \mathrm{~g}$ da silagem, colocados em bandejas de alumínio e levados para a estufa de circulação de ar a $55^{\circ} \mathrm{C}$ por 72 horas, e, posteriormente, foram triturados em moinho com peneira de crivos de $1 \mathrm{~mm}$ e armazenados em recipientes fechados.

Para o ensaio da estabilidade aeróbia, foram separados $500 \mathrm{~g}$ de cada repetição em potes plásticos sem tampa com capacidade para $1 \mathrm{~kg}$, esses potes foram acondicionados em sala com temperatura controlada $\left(25^{\circ} \mathrm{C}\right)$, a temperatura e o $\mathrm{pH}$ foram aferidos a cada doze horas ( 8 h e 20 h), durante sete dias, totalizando 168 horas de exposição aeróbia.

As perdas por gases (PG), as perdas por efluentes (PE) e recuperação de matéria seca (RMS) foram quantificadas de acordo com as equações propostas por Paziani et al. (2006). A determinação das perdas por gases foi calculada pela diferença de peso da massa de forragem no momento da ensilagem e da abertura e seus respectivos teores de MS (Equação 1). (fonte: TNR 10 - justificado - espaço 1,5).

$$
P G=\frac{(P f e-P a b)}{(M F f e x M S f e)} \times 100
$$

Em que: $\mathrm{PG}=$ perda por gases $(\% \mathrm{MS}) ; \mathrm{Pfe}=$ peso do silo experimental cheio no fechamento $(\mathrm{kg}) ; \mathrm{Pab}=$ peso do silo experimental cheio na abertura $(\mathrm{kg}) ; \mathrm{MFfe}=$ massa de forragem no fechamento $(\mathrm{kg}) ; \mathrm{MSfe}=$ teor de matéria seca da forragem no fechamento (\% MS).

As perdas por efluentes foram estimadas pela diferença de peso do silo experimental vazio na abertura e no fechamento do processo de ensilagem (Equação 2).

$$
P E=\frac{(P a b-P f e)}{(M F f e)} x 100
$$

Em que: $\mathrm{PE}=$ produção de efluente $(\mathrm{kg}$ t-1 massa verde); $\mathrm{Pab}=$ peso do conjunto (silo experimental + tampa) vazio na abertura, $(\mathrm{kg}) ; \mathrm{Pfe}=$ peso do conjunto (silo experimental + tampa) vazio no fechamento, $(\mathrm{kg}) ; \mathrm{MFfe}=$ massa de forragem no fechamento $(\mathrm{kg})$.

O índice de recuperação de matéria seca (RMS) foi obtido através da diferença de peso obtida pela pesagem da massa de forragem nos momentos da ensilagem e da abertura e seus respectivos teores de MS (Equação 3).

$$
\text { RMS }=\frac{(\text { MFab } \times \text { MSad })}{(\text { MFfe } \times \text { MSfe })} \times 100
$$

Em que: RMS = índice de recuperação de matéria seca (\%); MFab = massa de forragem na abertura (kg); MSab = teor de matéria seca da forragem na abertura (\%); MFfe = massa de forragem no fechamento $(\mathrm{kg}) ; \mathrm{MSfe}=$ teor de matéria seca da forragem no fechamento (\%).

As composições químico-bromatológicas das amostras in natura e da silagem para a matéria seca (MS), matéria mineral (MM), matéria orgânica (MO) e proteína bruta (PB) foram realizadas seguindo as recomendações de Silva e Queiroz (2002); já a fibra em detergente neutro (FDN) e a fibra em detergente ácido (FDA), de acordo com Van Soest, Robertson e Lewis (1991). 
Tabela 1. Composição químico-bromatológica do capim-elefante e do resíduo de açaí em diferentes pontos de coletas.

\begin{tabular}{lccccc}
\hline \multirow{2}{*}{ VARIÁVEL $^{1}$} & \multicolumn{3}{c}{ Resíduo de açaí (15\%) } & \multirow{2}{*}{ Capim-elefante } \\
\cline { 2 - 5 } & Natureza & Tapajós & Nativo & Alemão & \\
\hline MS (g/kg MN) & 298,56 & 282,34 & 306,65 & 309,94 & 250,94 \\
MM (g/kg MS) & 74,68 & 73,80 & 75,98 & 79,72 & 87,44 \\
MO (g/kg MS) & 925,32 & 926,20 & 924,02 & 920,28 & 912,56 \\
FDN (g/kg MS) & 646,18 & 641,54 & 639,24 & 639,02 & 659,00 \\
FDA (g/kg MS) & 461,80 & 472,70 & 453,32 & 460,80 & 472,22 \\
PB (g/kg MS) & 58,62 & 57,28 & 60,82 & 65,86 & 64,16 \\
\hline
\end{tabular}

${ }^{1} \mathrm{MN}=$ Matéria natural; MS = Matéria seca; $\mathrm{MM}=$ Matéria mineral; MO = Matéria orgânica; FDN = Fibra em detergente neutro; FDA = Fibra em detergente ácido e PB = Proteína bruta. Fonte: Autores.

O delineamento experimental adotado foi o inteiramente casualizado. Os dados obtidos foram submetidos à análise de variância utilizando-se o pacote estatístico SISVAR 5.7 e as médias comparadas pelo teste de Tukey, em nível de 5\% de probabilidade.

\section{Resultados e Discussão}

Nas avaliações sensoriais das silagens de capim-elefante com e sem a adição de resíduo de açaí, todas as silagens foram classificadas como "boa a muito boa" em relação ao aspecto nutritivo (Tabela 2). Foram observados quanto aos aspectos sanitários das silagens avaliadas ausência de leveduras e de odores indesejáveis, sendo classificadas como "boa a muito boa".

Sugere-se que houve boa compactação e vedação adequadas, em que se observou odor ácido característico, indicando presença de ácidos que favorecem o processo fermentativo, provavelmente, por adequada compactação que promove expulsão do ar nas partículas da massa ensilada e evitar aumento da temperatura por redução da fase aeróbica (Florentino et al., 2020), resultando em boa característica sensorial da silagem.

Tabela 2. Avaliação sensorial das silagens de capim-elefante com e sem resíduo de açaí em diferentes pontos de coleta.

\begin{tabular}{cccc}
\hline \multicolumn{4}{c}{ Características nutricionais } \\
\hline Tratamento & Pontuação Total & Classificação* & Parâmetro* \\
\hline Capim-elefante & 21 & Boa a Muito Boa & 21 a 25 \\
Natureza & 21 & Boa a Muito Boa & 21 a 25 \\
Tapajós & 22 & Boa a Muito Boa & 21 a 25 \\
Nativo & 25 & Boa a Muito Boa & 21 a 25 \\
Alemão & 25 & Boa a Muito Boa & 21 a 25 \\
& Características do aspecto sanitário & \\
\hline Tratamento & Pontuação Total & Classificação* & Parâmetro* \\
\hline Capim-elefante & $-0,4$ & Boa a Muito Boa & 0 a -5 \\
Natureza & 0 & Boa a Muito Boa & 0 a -5 \\
Tapajós & $-0,4$ & Boa a Muito Boa & 0 a -5 \\
Nativo & 0 & Boa a Muito Boa & 0 a -5 \\
Alemão & 0 & Boa a Muito Boa & 0 a -5 \\
\hline
\end{tabular}

*Conforme critérios estabelecidos por Meyer et al. (1989). Fonte: Autores. 
Os valores da composição química para Matéria Seca (MS); Matéria Mineral (MM); Fibra em Detergente Neutro (FDN); Fibra em Detergente ácido (FDA) e Proteína Bruta (PB) das silagens de capim-elefante com adição de resíduo de açaí são apresentadas na Tabela 3.

Tabela 3. Composição química das silagens de capim-elefante com e sem resíduo de açaí em diferentes pontos de coleta.

\begin{tabular}{llllll}
\hline \multirow{2}{*}{ VARIÁVEL $^{1}$} & \multicolumn{4}{c}{ Resíduo de açaí (15\%) } & \multirow{2}{*}{ Capim-elefante } \\
\cline { 2 - 5 } & Natureza & Tapajós & Nativo & Alemão & \\
\hline MS (g/kg MN) & $291,86 \mathrm{a}$ & $268,64 \mathrm{~b}$ & $297,16 \mathrm{a}$ & $299,66 \mathrm{a}$ & $247,82 \mathrm{c}$ \\
MM (g/kg MS) & $69,26 \mathrm{~b}$ & $74,46 \mathrm{~b}$ & $71,74 \mathrm{~b}$ & $70,86 \mathrm{~b}$ & $86,32 \mathrm{a}$ \\
MO (g/kg MS) & $930,74 \mathrm{a}$ & $925,54 \mathrm{a}$ & $928,26 \mathrm{a}$ & $929,14 \mathrm{a}$ & $913,68 \mathrm{~b}$ \\
FDN (g/kg MS) & $665,32 \mathrm{a}$ & $679,02 \mathrm{a}$ & $661,3 \mathrm{ab}$ & $681,38 \mathrm{a}$ & $631,24 \mathrm{~b}$ \\
FDA (g/kg MS) & $450,96 \mathrm{a}$ & $465,26 \mathrm{a}$ & $454,78 \mathrm{a}$ & $472,84 \mathrm{a}$ & $444,94 \mathrm{a}$ \\
PB (g/kg MS) & $65,74 \mathrm{~b}$ & $66,54 \mathrm{ab}$ & $70,42 \mathrm{a}$ & $68,06 \mathrm{ab}$ & $69,54 \mathrm{ab}$ \\
\hline
\end{tabular}

${ }^{1} \mathrm{MN}=$ Matéria natural; $\mathrm{MS}=$ matéria seca; $\mathrm{MM}=$ matéria mineral; $\mathrm{MO}=$ matéria orgânica; FDN = fibra em detergente neutro; FDA = fibra em detergente ácido e $\mathrm{PB}=$ proteína bruta.

${ }^{1}$ Médias seguidas de letras diferentes na mesma linha diferem entre si pelo teste de Tukey a 5\% de probabilidade.

Fonte: Autores.

Houve aumento $(\mathrm{P}<0,05)$ no teor de MS das silagens com a adição de $15 \%$ de resíduo de açaí. Os tratamentos Nativo $(297,16 \mathrm{~g} / \mathrm{kg})$, Alemão $(299,66 \mathrm{~g} / \mathrm{kg})$ e Natureza $(291,86 \mathrm{~g} / \mathrm{kg})$ apresentaram os maiores valores de MS em relação ao tratamento sem adição de resíduo de açaí $(247,82 \mathrm{~g} / \mathrm{kg})$, isso pode ser atribuído ao alto teor de MS do açaí, de $87,50 \%$ (Araújo, 2016).

Barcelos, Carvalho, Tavares e Gonçalves (2018) relataram que o teor de MS é um indicativo de adequada fermentação e boa qualidade das silagens, pois valores baixos para a cultura capim-elefante como encontrado no presente trabalho (247,82 g/kg MN), prejudicam o processo fermentativo. Segundo Retore, Alves, Orrico Júnior e Mendes (2020), para a obtenção de uma silagem de boa qualidade, o teor de MS deve variar de $28 \%$ a 34\%. Considerando esses valores, pode-se observar que somente as silagens com resíduos Natureza, Nativo e Alemão (Tabela 1) obtiveram valores de MS desejáveis para ocorrência de uma boa fermentação.

Foi verificado efeito significativo $(\mathrm{P}<0,05)$ quanto ao teor de $\mathrm{MM}$ onde o tratamento sem adição de resíduo de açaí apresentou maior teor $(86,32 \mathrm{~g} / \mathrm{kg})$ em relação aos demais tratamentos. Estes resultados sugerem que a inclusão de açaí, que tem menor teor de MM em relação à forragem, possibilitou a redução do teor de MM no material ensilado.

Diferentemente, Aguiar (2019) verificando Parâmetros físico-quimícos de silagens de milho na região de Rio VerdeGO, onde não observou diferenças significativas entre os tratamentos, com média de 3,9\%.

Verificou-se efeito significativo $(\mathrm{P}<0,05)$ no teor de FDN, onde o menor valor foi observado para o tratamento sem adição de resíduo $(631,24 \mathrm{~g} / \mathrm{kg})$ em relação aos tratamentos Natureza, Tapajós e Alemão. Esses resultados já eram esperados com a adição de resíduo de açaí nas silagens, por aumentar o teor de carboidratos fibrosos das silagens.

Segundo Van Soest (1994), dietas contendo menores teores de FDN reduz o tempo de ruminação, propicia uma maior taxa de passagem e estimula o consumo. O mesmo autor relata que teores de FDN acima de $60 \%$ podem limitar o consumo dos alimentos pelos animais ruminantes. Desta forma, as silagens avaliadas neste experimento poderiam reduzir o consumo.

Não houve efeito dos tratamentos sobre os teores de FDA das silagens avaliadas em que foi obtido o valor médio de $45,73 \%$, este percentual é inferior ao observado por Maia et al. (2015) que ao avaliar valor nutritivo de silagens de capim elefante com 15\% de resíduo da agroindústria da acerola observou teor de 57,29\% de FDA. Lira Júnior et al. (2018) 
mencionam que é desejável redução do teor de FDA na silagem, pois, compõe a fração indigestível da fração fibrosa dos alimentos volumosos.

Van Soest (1994) relata que teores de 40\% de FDA acarretam baixa ingestão de alimento e afetam negativamente a digestibilidade. Com base neste parâmetro, as silagens com e sem adição de resíduo de açaí podem causar limitação do consumo, pois as FDA das silagens variaram de $44,49 \%$ a $47,28 \%$.

A adição de açaí na ensilagem de capim-elefante não elevou os teores de PB nas silagens, devido provavelmente, as perdas por efluente de compostos nitrogenados (Paula et al., 2020). No entanto, houve diferença significativa entre o teor de PB da silagem com adição de resíduo do açaí Nativo $(70,42 \mathrm{~g} / \mathrm{kg})$ e o Natureza $(65,74 \mathrm{~g} / \mathrm{kg})$. Monteiro et al. (2011) observaram, em seu experimento, 7,09\% de PB ao adicionar $10 \%$ de casca de soja em silagem com capim elefante, teor similar ao obtido na silagem com aditivo de açaí Nativo.

Os teores de PB das silagens variaram de $65,74 \mathrm{~g} / \mathrm{kg}$ a 70,42g/kg (Tabela 3). Com exceção da silagem Nativo, todas as silagens apresentaram teor de PB abaixo de 7\%, percentual mínimo recomendado para efetiva fermentação microbiana ruminal (Van Soest, 1994).

Houve efeito de tratamentos $(\mathrm{P}<0,05)$ sobre o $\mathrm{pH}$ das silagens (Tabela 4). As silagens Natureza e Nativo apresentaram menores valores de $\mathrm{pH}$ quando comparadas à silagem Alemão, em que o aditivo do resíduo açaí foi eficiente para reduzir o $\mathrm{pH}$ da silagem de capim-elefante.

De acordo com este parâmetro, todas as silagens podem ser classificadas como bem preservadas, uma vez que o pH se manteve abaixo do valor máximo permitido para a caracterização de silagens de boa qualidade, ou seja, de 4,2 (McDonald et al., 1991).

A silagem sem adição de resíduo apresentou menor $(\mathrm{P}<0,05)$ TIS $\left(23,32^{\circ} \mathrm{C}\right)$ em relação à silagem Natureza $\left(25,04^{\circ} \mathrm{C}\right)$.

Azevedo et al. (2020) salientam que o aumento da temperatura ambiente causa deterioração das silagens, obtendo efeito significativo na atividade microbiana na fermentação da silagem, e apesar das diferenças significativas entre as silagens avaliadas, todas apresentaram temperaturas abaixo de $30^{\circ} \mathrm{C}$, indicando boa compactação e, consequentemente, ausência de oxigênio.

Quanto aos teores de N-NH3/NT houve diferença significativa $(\mathrm{P}<0,05)$ entre os tratamentos, a silagem Tapajós apresentou o maior teor $(3,60 \%)$ em relação às demais silagens avaliadas.

Tabela 4. Valores médios de pH, TIS, N-NH 3 , RMS, PG e PE das silagens de capim-elefante sem e com resíduo de açaí em diferentes pontos de coleta.

\begin{tabular}{|c|c|c|c|c|c|}
\hline \multirow{2}{*}{ VARIÁVEL ${ }^{1}$} & \multicolumn{4}{|c|}{ Ponto de coleta do resíduo de açaí } & \multirow{2}{*}{ Capim-elefante } \\
\hline & Natureza & Tapajós & Nativo & Alemão & \\
\hline $\mathrm{pH}$ & $3,70 \mathrm{~b}$ & $3,96 \mathrm{ab}$ & $3,70 \mathrm{~b}$ & $4,10 \mathrm{a}$ & $3,84 a b$ \\
\hline TIS & $25,04 \mathrm{a}$ & $24,36 \mathrm{ab}$ & $24,26 a b$ & $23,78 \mathrm{bc}$ & $23,32 \mathrm{c}$ \\
\hline $\mathrm{N}-\mathrm{NH}_{3} / \mathrm{NT}(\%)$ & $1,97 \mathrm{~b}$ & $3,60 \mathrm{a}$ & $2,26 \mathrm{~b}$ & $2,37 \mathrm{~b}$ & $1,60 \mathrm{~b}$ \\
\hline $\mathrm{RMS}(\mathrm{g} / \mathrm{kg})$ & $973,16 \mathrm{a}$ & $944,06 \mathrm{a}$ & $963,34 \mathrm{a}$ & $958,52 \mathrm{a}$ & $982,9 \mathrm{a}$ \\
\hline PG (g/kg MS) & $0,178 b$ & $0,266 \mathrm{ab}$ & $0,186 a b$ & $0,268 \mathrm{a}$ & $0,232 \mathrm{ab}$ \\
\hline PE (kg.t $\left.\mathrm{t}^{-1} \mathrm{MV}\right)$ & $0,031 b$ & $0,079 \mathrm{a}$ & $0,046 \mathrm{ab}$ & $0,056 \mathrm{ab}$ & $0,055 \mathrm{ab}$ \\
\hline
\end{tabular}

${ }^{1} \mathrm{pH}$ = potencial hidrogeniônico; TIS = Temperatura no interior do silo; $\mathrm{N}-\mathrm{NH}_{3}=$ nitrogênio amoniacal; $\mathrm{RMS}=$ recuperação de matéria seca; $\mathrm{PG}=$ perdas por gases; $\mathrm{PE}=$ perdas por efluentes .

${ }^{1}$ Médias seguidas de letras diferentes na mesma linha diferem entre si pelo teste de Tukey a 5\% de probabilidade.

Fonte: Autores. 
Segundo Rigueira et al. (2017) o teor de $\mathrm{N}-\mathrm{NH}_{3}$ em conjunto com o pH é um dos parâmetros de perdas de nitrogênio no padrão fermentativo da silagem. Nogueira (1995) relatou valores de nitrogênio amoniacal variando de, 1,5\% a $2,18 \%$ de $\mathrm{N}-\mathrm{NH}_{3} / \mathrm{NT}$. Um baixo teor de $\mathrm{N}-\mathrm{NH}_{3} / \mathrm{NT}$ na silagem, inferior a $10 \%$ do nitrogênio total, indica que o processo de fermentação não resultou em quebra excessiva da proteína em amônia (Muck, 1988; Van Soest, 1994). Neste sentido, as silagens estudadas apresentaram fermentações adequadas.

Não houve efeito significativo ( $\mathrm{P}>0,05)$ nos teores de RMS, a média entre os tratamentos foi de $96,44 \%$, isso indica inibição de bactérias heterofermentativas e bactérias proteolíticas, responsáveis pela elevação das perdas de matéria seca. Lima (2013) observou média de 95,79\% de RMS ao avaliar silagem de subproduto da mandioca, excelente aditivo absorvente como resíduo de açaí, em seu experimento.

Nas PG, observou-se diferença $(\mathrm{P}<0,05)$ entre os tratamentos. A silagem com adição de açaí Alemão apresentou maior perda por gases $(0,268 \mathrm{~g} / \mathrm{kg})$ em relação ao tratamento Natureza $(0,178 \mathrm{~g} / \mathrm{kg})$, mesmo havendo diferenças, os teores são considerados baixos quando comparados com a literatura. Teodoro e Grecco (2016), ao avaliar silagem de capim com adição de $10 \%$ de milho moído, verificaram perdas por gases de $2,42 \%$.

Para PE, observaram-se efeitos $(\mathrm{P}<0,05)$ dos tratamentos, a silagem com resíduo de açaí Tapajós apresentou maior perda por efluente $\left(0,079 \mathrm{~kg} \cdot \mathrm{t}^{-1} \mathrm{MV}\right)$ quando comparada à silagem com resíduo de Natureza $\left(0,031 \mathrm{~kg} \cdot \mathrm{t}^{-1} \mathrm{MV}\right)$, os índices de perdas por efluentes apresentados no presente trabalho estão abaixo aos descritos por Oliveira et al. (2010), para silagem de milho (20,4 kg.t. $\left.{ }^{-1} \mathrm{MV}\right)$, que é considerada como padrão de qualidade para volumosos.

$\mathrm{Na}$ avaliação da estabilidade aeróbia, verificou-se que as temperaturas das silagens foram influenciadas $(\mathrm{P}<0,05)$ pelos tratamentos e pelo tempo em que ficaram expostas ao oxigênio (Figura 1).

A silagem Tapajós apresentou a menor estabilidade aeróbia, pois apresentou elevação de $2^{\circ} \mathrm{C}$, em relação à temperatura ambiente, em até 36 horas de exposição. No entanto, após esse tempo, a silagem manteve-se estável até 168 horas.

Houve diferenças significativas $(\mathrm{P}<0,05)$ entre os tratamentos para o tempo de 72 horas de exposição aeróbia, as silagens Natureza e Nativo apresentaram os maiores valores de temperatura em relação as silagens Tapajós e Alemão. Observou-se ainda, em ambas as silagens, a quebra da estabilidade aeróbia. Após esse tempo, as silagens mantiveram-se estáveis até 168 horas.

Figura 1. Variação da temperatura das silagens de capim-elefante com resíduo de açaí.

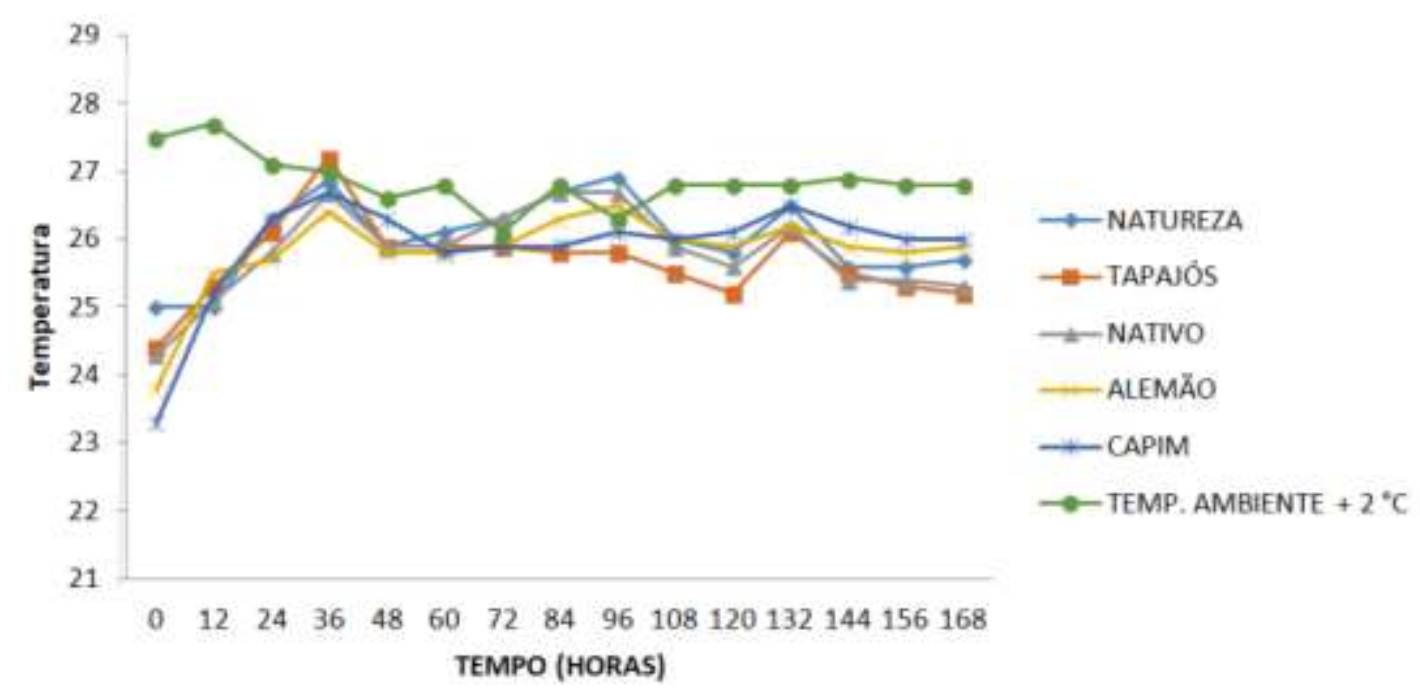

Fonte: Autores. 
A maior estabilidade aeróbia foi observada nas silagens de capim-elefante e Alemão, tais silagens permaneceram estáveis por até 168 horas, que pode estar relacionada às menores concentrações de carboidratos solúveis residuais nestas silagens com consequente aumento no teor de ácido propiônico, sendo as bactérias produtoras de ácido propiônico avaliadas como colaboradoras da estabilidade aeróbia das silagens por inibirem microrganismos indesejáveis como fungos filamentosos e leveduras (McDonald et al., 1991; Souza et al., 2009).

Araújo (2016) avaliando a inclusão do caroço de açaí em silagem de Capim-Canarana sobre a qualidade fermentativa e a estabilidade aeróbia da silagem, observou que a silagem de Capim-Canarana, sem adição de caroço de açaí, apresentou baixa estabilidade aeróbia e quando adicionada até $15 \%$ de caroço de açaí à silagem ocorria aumento da estabilidade. No presente estudo, não foi verificado aumento da estabilidade com a adição de açaí no capim-elefante.

Os valores de $\mathrm{pH}$ apresentaram diferença $(\mathrm{P}<0,05)$ entre as silagens com o decorrer das horas de exposição aeróbia (Figura 2). Nas primeiras 24 horas ( 0 h, 12 h e 24 h) de exposição os maiores valores foram registrados para a silagem Alemão $(4,10,4,20$ e 4,14, respectivamente) e os menores para as silagens Natureza e Nativo de 3,70 e 3,70; 3,70 e 3,72; 3,68 e 3,70, respectivamente. Nos tempos de 36 e 48 horas a silagem Alemão apresentou os maiores valores de pH $(4,28$ e 4,48, respectivamente) em relação à silagem Nativo (3,76 e 3,60, respectivamente).

Não houve diferença significativa $(\mathrm{P}>0,05)$ nos valores de $\mathrm{pH}$ entre os tratamentos nos tempos de 60 a 120 horas e de 144 a 168 horas. No entanto, foram observados aumentos crescentes nos valores de $\mathrm{pH}$ das silagens com o tempo de exposição aeróbia, sendo que a partir de 84 horas as médias de $\mathrm{pH}$ das silagens ultrapassaram a 5,0.

No geral, houve grande variação nos valores de $\mathrm{pH}$ durante o período de exposição aeróbia, de modo que foi possível observar valores próximos de 3,6 até 7,9 nas silagens avaliadas.

Segundo Macêdo, César Neto, Silva e Santos (2021), em geral, silagens de capins tropicais como capim elefante, possuem valores de pH elevado e menores concentrações de ácido lático, resultando em maiores concentrações de ácido butírico. Esse aumento dos valores de $\mathrm{pH}$ das silagens durante a avaliação da estabilidade pode ser um indicativo de deterioração devido à ação de microrganismos aeróbios, o que pode ter resultado nesse aumento do pH das silagens de capim elefante com resíduo de açaí avaliadas após exposição ao oxigênio.

Figura 2. Variação do pH das silagens de capim-elefante com resíduo de açaí.

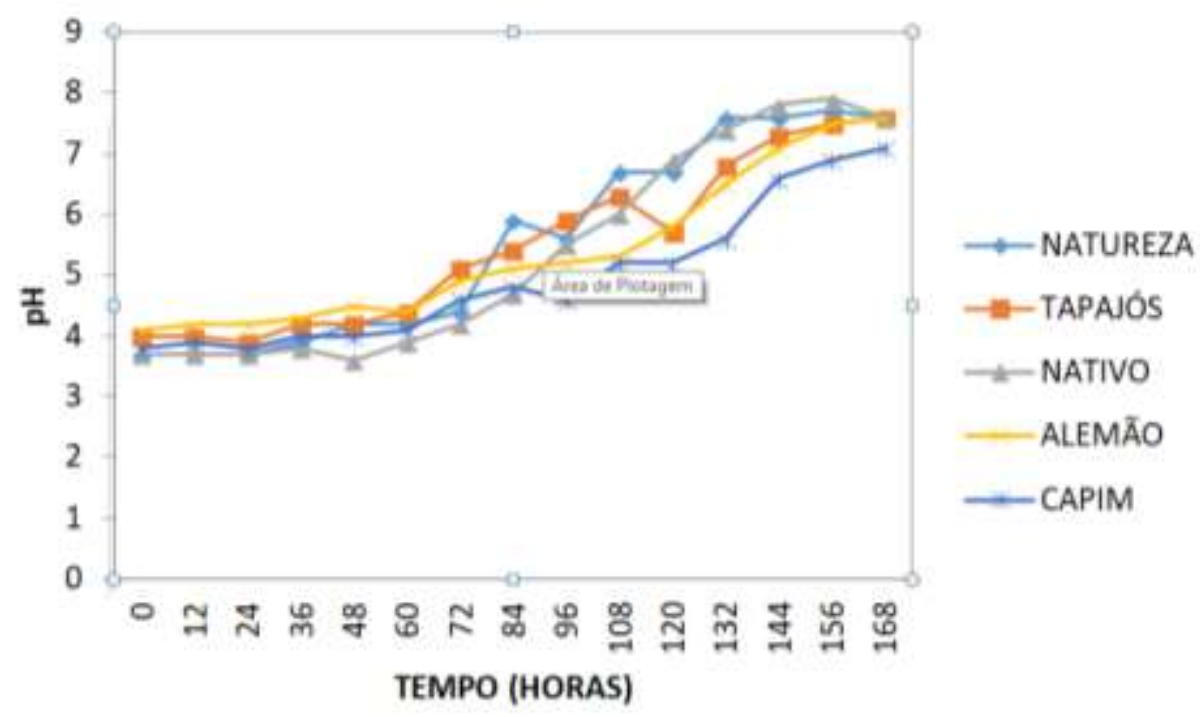

Fonte: Autores. 


\section{Conclusão}

O uso de resíduo de $15 \%$ de açaí como aditivo na silagem de capim-elefante mantém as características sensoriais e nutritivas de uma silagem de boa qualidade independente da origem do resíduo.

As silagens apresentaram diferenças quanto ao padrão fermentativo, à composição químico-bromatológica bromatológica e a estabilidade aeróbia em função da origem do resíduo.

A silagem de capim-elefante e a silagem aditivada com resíduo do açaí do Alemão apresentam melhor estabilidade aeróbica e perfil fermentativo.

Recomenda-se que mais estudos sejam realizados visando formas de aproveitamento do subproduto de açaí na alimentação animal, além de melhorar seu valor nutricional.

\section{Agradecimentos}

Á UFOPA e ao programa de bolsas de iniciação cientifica pelo auxílio financeiro e pela estrutura disponibilizada para execução deste experimento.

\section{Referências}

Aguiar, M. S. (2019). Parâmetros físico-químicos de silagens de milho na região de Rio Verde-GO. Trabalho de Conclusão de Curso. Faculdade de Medicina

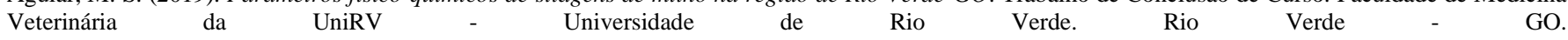
https://www.unirv.edu.br/conteudos/fckfiles/files/MATEUS\%20DA\%20SILVA\%20AGUIAR.pdf

Amaral, C. da S., Lima, J. S. de, Pereira, K. P., Araújo Filho, J. T de, Costa, I. C. A. \& Silva, M. G. P. da. (2021). Perfil metabólico de ovinos alimentados com silagem de subproduto de maracujá. Diversitas Journal, 6(1), 1711-20.

Araújo, J. A. S. (2016). Níveis de inclusão de caroço de açaí em silagem de capim-canarana, Santarém. Trabalho de Conclusão de Curso. Instituto de Biodiversidade e Florestas, Universidade Federal do Oeste do Pará, Santarém.

Azevedo M. M. R., Guimaraes, A. K. V., Cabral, I. dos S., Barbosa, C. R., Machado, L. S., Pantoja, J. de C., \& Amaral, T. E. dos S. et al. (2020). Características de silagens de capim-elefante (Pennisetum purpureum Schum.) com níveis de inclusão de moringa (Moringa oleífera Lam.). Brazilian Journal of Development, 6(9), 71418-33. http://doi.org/10.34117/bjdv6n9-549

Barcelos, A. F., Carvalho, J. R. R. de,Tavares, V. B., \& Gonçalves, C. C. de M. (2018). Valor nutritivo e características fermentativas da silagem de capimelefante com diferentes proporções de casca de café. Ciência Animal Brasileira, 19, e-27432. https://doi.org/10.1590/1809-6891v19e-27432

Borges, B. R. S., Negrão, F. de M., Zanine, A. de M., Machado, A., Caldeira, F. H. B., \& Lins, T. O. J. D’A. (2018). Potencial da ensilagem de capimbraquiaria com inclusão de farelo de arroz: Revisão. PUBVET, 12(2),150. https://doi.org/10.22256/pubvet.v12n2a28.1-9

Cândido, M. J. D., \& Furtado, R. N. (Orgs). (2020). Estoque de forragem para a seca: produção e utilização de silagem. Fortaleza: Imprensa Universitária UFC. http://www.repositorio.ufc.br/bitstream/riufc/53687/1/2020_liv_mjdcandido.pdf

Florentino, L. da S., Nascimento, I. R., Santos, R. M. dos., Borchat, K. D., Oliveira, A. A. de, \& Silva, M. J. dos S. (2020). Análise das perdas em silagem de cana-de-açúcar submetida a diferentes tipos de aditivos químicos. Enciclopédia Biosfera, 17(34), 22-31. https://doi.org/10.18677/EnciBio_2020D3

Lima, J. S. (2013). Silagem de subprodutos da mandioca como fonte alimentar de ruminantes. Programa de Pós-Graduação em Ciência Animal e Pastagens, Universidade Federal Rural de Pernambuco. http://ww2.pgcap.ufrpe.br/sites/ww2.prppg.ufrpe.br/files/jucelane_salvino_de_lima.pdf

Lira Junior, W. B., Bezerra, S. B. L., Paula, T.A., Beelen, R. N., Amorim, P. L., \& Beelen, P. M. G. (2018). Características de silagens de capim-elefante (Pennisetum purpureum) e casca de maracujá in natura. Arquivo Brasileiro de Medicina Veterinária e Zootecnia, 70(3), 905-912. https://doi.org/10.1590/1678-4162-9410

Macêdo, A. J. da. S., César Neto, J. M., Silva, M. A. da, \& Santos, E. M. (2021). Potencialidades e limitações de plantas forrageiras para ensilagem: Revisão de Literatura. Revista Brasileira de Higiene e Sanidade Animal, 15(1), 1-17. http://www.repositorio.ufc.br/handle/riufc/55811

Maia, I. S. A. S., Braga, A. P., Gerra, D. G. F., \& Lima Júnior, D. M. (2015). Valor nutritivo de silagens de capim elefante com níveis crescentes de resíduo da agroindústria da acerola. Acta Veterinaria Brasilica, 9(2), 190-4. https://doi.org/10.21708/avb.2015.9.2.5238

McDonald, P., Henderson, A. R., \& Heron, S. J. E. (1991). The biochemistry of silage. $2 . \quad$ ed. Marlow: Chalcombe. 340p. https://doi.org/10.1017/S0014479700023115

Meyer, H., Bronsch, K., \& Leibetseder, J. (1989). Supplemente zu vorlesungen und übungen in der tierernährung. Hannover: Verlag M. e H. Schaper. 255p.

Monteiro, I. J. G., Abreu, J. G., Cabral, L. S; Ribeiro, M. D., \& Reis, R. H. P. (2011). Silagem de capim-elefante aditivada com produtos alternativos. Acta Scientiarum. Animal Sciences, 33(4), 347-52. DOI: 10.4025/actascianimsci.v33i4.12629 
Muck, R. E. (1988). Factors influencing silage quality and their implications for management. Journal of Dairy Science, 71(11), 2992-3002. https://doi.org/10.3168/jds.S0022-0302(88)79897-5

Nogueira, F. A. S. (1995). Qualidade das silagens de genótipos de sorgo de porte baixo com e sem tanino e de colmo seco e suculento, e seus padrões de fermentação, em condições de laboratório. 1995. 78p. Dissertação (Mestrado em Zootecnia) Escola de Veterinária da Universidade Federal Minas Gerais.

Nogueira, M. S. (2015). Perfil fermentativo e composição química de silagens de palma forrageira enriquecidas com fontes proteica, energética e fibrosa. 58 p. Dissertação (Mestrado em Zootecnia) Universidade Federal da Paraíba.

Oliveira, L. B., Pires, A. J. V., Carvalho, G. G. P. de, Ribeiro, L. S. O., Almeida, V. V. de, \& Peixoto, C. A. M. (2010). Perdas e valor nutritivo de silagens de milho, sorgo-sudão, sorgo forrageiro e girassol. Revista Brasileira de Zootecnia, 39(1), 61-7. https://doi.org/10.1590/S1516-35982010000100008

Paula, P. R. P., Neiva Júnior, A. P., Souza, W. L. de, Abreu, M. J. I. de, Teixeira, R. M. A., Cappelle, E. R., \& Tavares, V. B. (2020). Composição bromatológica da silagem de capim-elefante BRS Capiaçu com inclusão de fubá de milho. PUBVET, 14(10), 1-11. https://doi.org/10.31533/pubvet.v14n10a682.1-11

Paziani, S. de F., Nussio, L. G., Loures, D. R. S., Igarasi, M. S., Pedroso, A de F., \& José Maria, L. (2006). Influência do teor de matéria seca e do inoculante bacteriano nas características físicas e químicas da silagem de capim Tanzânia. Acta Scientiarum. Animal Science, 28(3), 265-71. https://www.redalyc.org/articulo.oa?id=303126484004

Pereira, A. S., Shitsuka, D. M., Parreira, F. J., \& Shitsuka, R. (2018). Metodologia da pesquisa científica. 1.ed. Santa Maria, RS: UFSM, NTE.

Retore, M., Alves, J. P., Orrico Junior, M. A. P., \& Mendes, S. S. (2020). Qualidade da silagem do capim-elefante BRS Capiaçu. Comunicado Técnico 261. Dourados - MS. https://www.infoteca.cnptia.embrapa.br/infoteca/bitstream/doc/1130009/1/COT-261-2020.pdf

Ribeiro, L. S. O., Pires, A. J. V., Carvalho, G. G. P. de., Pereira, M. L. A., Santos, A. B. dos, \& Rocha, L. C., (2014) Características fermentativas, composição química e fracionamento de carboidratos e proteínas de silagem de capim-elefante emurchecido ou com adição de torta de mamona. Semina: Ciências Agrárias, 35(3), 1447-62. https://doi.org/10.5433/1679-0359.2014v35n3p1447

Rigueira, J. P. S., Monção, F. P., Sales, E. C. J. de, Brant, L. M. S., Pires, D. A. de A., Matos, A. M., ... Rocha Júnior, V. R. (2017). Níveis de glicerina bruta na ensilagem de capim Tifton 85 (Cynodon dactylon): perfil fermentativo e valor nutricional. Revista de Ciências Agrárias, 40(3), 655-63. http://dx.doi.org/10.19084/RCA16141R

Silva, D. J., \& Queiroz, A. C. (2002). Análise de alimentos: métodos químicos e biológicos. 3.ed. Viçosa, MG: Editora UFV. 235p.

Souza, W. F., Rigueira, J. P. S., Rosa,L. O., Cunha, L. R. da, Chave, K. da S., \& Ferreira , C. L. de L. F. (2009). Papel da fermentação propionica na produção de silagem. PUBVET, 3(3), 495. http://www.pubvet.com.br/texto.php?id=500

Tavares, G. dos S., Homma, A. K. O., Menezes, A. J. E.A. de, \& Palheta, M. P. (2020). Análise da produção e comercialização de açaí no estado do Pará, Brasil. International Journal of Development Research, 10(4), 35215-21.

Teodoro, E. D., \& Grecco, F. C. A. R. (2016). Perdas de gases e efluentes de silagens de capim elefante com milho moído. $7^{\circ}$ Seminário de Iniciação Científica. Anais [... $\quad$ Universidade Norte do http://repositorio.pgsskroton.com/bitstream/123456789/4652/1/Perda\%20de\%20gases\%20e\%20efluentes\%20de\%20silagens\%20de\%20capim\%20V1.pdf

Van Soest, P. J. (1994). Nutritional ecology of the ruminant. 2.ed. Ithaca: Comstock. 476p.

Van Soest, P. J., Robertson, J. B., \& Lewis, B. A (1991). Methods for dietary fiber, neutral detergent fiber, and nonstarch polyssacarides in relation to animal nutrition. Journal of Dairy Science, 74(10), 3583-3597. https://doi.org/10.3168/jds.S0022-0302(91)78551-2 